\title{
Saltbiçim İşlemleri ve Taban Biçimleme
}

\author{
Aysun Kundurac1 \\ ORCID ID: 0000-0001-5250-7899 \\ Yeditepe Üniversitesi, Eğitim Fakültesi, Yabancı Diller Eğitimi Bölümü, \\ Kayışdă̆ı Cad., 34755, İstanbul \\ kunduraca@gmail.com \\ (Gönderilme tarihi 9 Şubat 2019; kabul edilme tarihi 16 Eylül 2019)
}

\begin{abstract}
ÖZ: Bu çalışma Türkçede ayrıklık (separationism, Beard, 1995: anlam ve biçimin ayrı düzlemselliği) ve ayrıklığın Türkçe gibi bitişimli dillerdeki önemi üzerinedir. Çalışma, anlam içermeyen saltbiçimsel (morphomic, Aronoff, 1994) türetimleri incelemektedir. Örneğin okuyиси sözcüğü, kök biçimin (oku) anlamı ve amaçlanan çıktı anlam 'okuyucu: okuma eylemini yapan' dışında bir anlam içermese de, yapı, amaçlanan anlamla etkileşen -CI eklenmesinden önce bir biçim daha içermektedir: $-I$ eklenmesi ile okuyu-. Bu gibi oluşumlarda anlam güdüsüz biçimsel işlemler devrededir, güdü yalnızca ulamsal ve biçimseldir. Yukarıda okuyиcu'dan önce elde edilen okuyu- gibi türevlerdeki $I$ eklenmesi, alanyazınında fark edilmeyerek, sonrasındaki - $C I$, -lI gibi eklerle birlikte algılanmıştır: *-ICI gibi. Oysaki, -I gibi özerk eklenmeler, biçimyapısı açısından önemlidir: (i) Anlam-biçim ayrıklığını, (ii) bağımlı ön/arabiçimleri ve (iii) biçimyapısının taban koşullarını ortaya çıkarmaktadır. Saltbiçimsel işlemler, ayrıca, kimi bilişsel dilbilim modellerinin (örn. van Langendonck, 2007) biçimsel dilbilim modellerini eleştirirken değindiği görüntüsellik ilkesine de açıkça aykırıdır; dilin yapısının dünya kavramlarına bağımlı olmadığı, kendine özgü olduğu anlaşılmaktadır.
\end{abstract}

Anahtar sözcükler: biçimbilim, taban, ayrıklık, adlaşma, türetim

\section{Purely Morphological Mechanisms and Base Formation}

ABSTRACT: This study concerns itself with separationism (Beard, 1995) in Turkish and the need for separationism in agglutinating languages as well. The study scrutinizes morphomic (cf. Aronoff, 1994) derivations, which are devoid of semantics. In the expression okuyиси 'reader', for instance, there is no other (intermediate) meaning than the meaning of the root $o k u$ - (read) and the target meaning of okиуиси 'reader: the doer of reading'. However, the derivative includes one more formal item, $-I$ with the output okuyu-, right before -CI suffixation. In such formations, morphomic operations, which are motivated morphologically and/or categorically, but not semantically, take place. The $-I$ 
suffixation yielding derivatives like okuyu- as above has been misconceived as a piece of suffixes following it, such as $-C I$ and $-l I$, i.e. $*_{-} I C I$. Importantly however, affixations like $-I$ contributes to understanding the nature of morphology: They indicate (i) affixations without meaning, (ii) the existence of preforms, and (iii) morphological base conditions. Morphomic operations, further, challenge iconicity, which cognitive linguistic models, such as van Langendonck (2007), are for when criticizing formal linguistics. Morphomic operations show that grammar cannot depend on purely world concepts.

Keywords: morphology, base, separationism, nominalization, derivation

\section{Giriş: Anlam-Biçim Ayrıklığı, Saltbiçim ve Biçimbirim}

Dilde ve biçimbilimde anlam-biçim ayrıklı̆̆ (separationism, Beard, 1995), anlamsal ve biçimsel bilgi ve değerleri ayrı ayrı açıklamakla kalmayıp bunların ötesinde verilerle de başa çıkabilmeyi sağlamaktadır. Bu çalışma anlam-biçim ayrıklığının Türkçe gibi biçimsel tipolojide çoğunlukla bitişimli davranışlar sergileyen dillerde de gerekli olduğunu göstermekte, anlamdan özerk, anlam içermeyen, anlamsal bir nedeni olmayan biçimleri irdelemektedir. 'anlam güdüsüz biçim' olarak da tanımlayabileceğimiz bu gibi salt biçim oluşumları hem ayrıklık hem de biçimyapısının ${ }^{1}$ dil dizgesindeki işlemleri ve amaçları açısından önemli çıkarımlar yapmamızı sağlamaktadır. Bu çalışma, Türkçede de yalnızca biçimsel/biçimyapısal amaçla oluşan salt biçim türevlerini gösterimlemekte, biçimyapısıyla ilgili özel bulguların yanında dilde biçimlerin, örneğin bilişselci yaklaşımların aksine, kavramsal yapıya ya da kavramsal ilişkilere dayanmak zorunda olmadığını ortaya çıkarmaktadır.

Aronoff (1994) ve Stump (2001) biçimbilimde saltbiçim (morphome) kavramını ortaya atmaktadır. morphọme 'saltbiçim' terimi, anlamlı/anlam işlevli en küçük dilsel birim morphẹme 'biçimbirim' ile karıştırılmamalıdır. Saltbiçimler sözdizim ya da anlambilgisiyle güdülenmeyen, yalnızca biçimbilgisel nedenlere bağlı olarak ortaya çıkan birimlerdir. Aronoff'un belirttiği gibi, örneğin, Latince gibi çekimsel sınıf içeren dillerde köklerin ya da tabanların çekime girmeden önce, belirli işlemlerden geçerek çekime hazır duruma (biçime) gelmesi gerekir. Bu gibi özellikler anlamla, sesle ya da sözdizimle güdülenmediğinden saltbiçimsel (morphomic) olarak değerlendirilmeli ve sözdizim ya da anlamla güdülenen diğer biçimsel özelliklerden (dizimbiçimsel (morphosyntactic), anlambiçimsel (morphosemantic)) ayrılmalıdır (krş. Sadler ve Spencer, 2001).

Maiden (2011) ve O'Neill (2013) de Aronoff (1994) ve Stump'in (2001) vurguladığı, yalnızca biçimbilgisi kaynaklı özelliklerin altını çizmektedir.

1 Bu çalışmada biçimyapısı terimi biçimbilgisinin işleme geçen, etkin durumu için kullanılmaktadır. 
Aronoff (1994) ve O’Neill (2013), örneğin Latincede üçüncü taban (third stem) olarak adlandırdıkları bir biçimi saltbiçim örnekleri arasında göstermektedir. ${ }^{2} \mathrm{Bu}$ taban türü sessel ve anlamsal olarak birbiriyle doğrudan bağlantısı olmayan bir dizi çekimsel ve türetimsel biçim için gereken girdiyi sağlamaktadır: özel bir taban biçimi (üçüncü taban). Latincede, örneğin, çekimsel olarak bitmişlik ortacı (past participle), gelecek ortacı (future participle), adeylem, türetimsel olarak da kılıcı/eden türü adlaşmaları oluştururken bu üçüncü taban türü kullanılmaktadır (Aronoff, 1994: 32-33; O’Neill, 2013: 222).

Tablo 1. Latincede düzenli eylem çekimleri

\begin{tabular}{llll}
\hline $\begin{array}{l}\text { Şimdi, Etken: } \\
\text { (Eylemlik) }\end{array}$ & Bitmişlik Ortac1 & Gelecek Ortacı & \\
\hline lauda-re & laudat- & laudat-ur & 'övmek' \\
mone-re & monit- & monit-ur & 'uyarmak' \\
audi-re & audit- & audit-ur & 'duymak' \\
\hline
\end{tabular}

Tablo 2. Latincede düzensiz eylem çekimleri

\begin{tabular}{llll}
\hline $\begin{array}{l}\text { Şimdi, Etken: } \\
\text { (Eylemlik) }\end{array}$ & Bitmişlik Ortac1 & Gelecek Ortac1 & \\
\hline fer-re & lat- & latur- & 'taşımak' \\
sistre-re & stat- & statur- & 'yerleştirmek' \\
esse & ---- & futur- & 'olmak' \\
\hline
\end{tabular}

Yukarıda Tablo 1 'de, ${ }^{3}$ öncelikle bitmişlik ortacı biçiminin eylem(lik) tabanına $t$ eklenmesi ile, gelecek ortacı biçiminin ise eylem(lik) tabanından değil, bitmişlik ortacını gösteren tabana -ur eklenmesi ile oluştuğunu görüyoruz. Tablo 2'de de bu duruma ek olarak, bitmişlik ortacı biçiminin düzensiz olması durumunda gelecek ortacı biçiminin de ona göre düzensizleştiğini görüyoruz.

Geleneksel yaklaşımlar, bu özelliklerden yola çıkarak gelecek ortacı biçiminin bitmişlikten türediğini düşünmekte, ancak bu durumda gelecek ortacı biçiminin aynı zamanda etken ancak bitmişlik ortacı biçiminin edilgen bir biçim olduğunu açıklayamamaktadır (Aronoff, 1994: 32-33). Matthews (1972), Mel'čuk (1991), Aronoff (1994) ve O'Neill (2013), bu gibi, bir biçimin diğerinden oluştuğu, anlama dayalı ama anlamca tutarsız yorumlamaları eleştirmekte ve Latincedeki bu karmaşıklığı saltbiçimlerle açıklamaktadır; Tablo 1 ve Tablo 2'de olduğu gibi, Latincede farklı kullanımlardaki ortaklığ biçime vermekte ve bitmişlik ortacı biçimini anlamdan özerk bir saltbiçim olarak

2 Latincedeki taban türleri ve altbiçimler için bkz. Aronoff (1994).

3 Tablo 1'deki veri, Aronoff'un (1994) Tablo 2.1'inden, Tablo 2'deki veri de Aronoff'un (1994) Tablo 2.2'sinden alınmıştır. 
değerlendirmektedir. Böylece, ilgili kullanımlar (bitmişlik ve gelecek ortacı) arasında anlam ilişkisi olmadığı halde aynı biçimin (3. tabanın) daima oluşması açıklanabilmektedir. Yani bir biçimin diğerinden anlama dayalı türemesi yerine farklı anlamlarda aynı biçim kullanılmaktadır; yukarıdaki durumlar temel bir anlamsal nedene değil biçimsel bir nedene dayanmaktadır. Farklı anlamların ortak noktası olan bu biçimsel birim, dizimbiçimsel ve anlambiçimsel düzlemlerden ayrı bir işlev olarak gösterilmektedir. ${ }^{4}$ Şekil 1'de O'Neill'ın gösterimini görüyoruz (O’Neill, 2013, Şekil 12. 1):

Şekil 1. O'Neill'ın biçimsel gösterimi

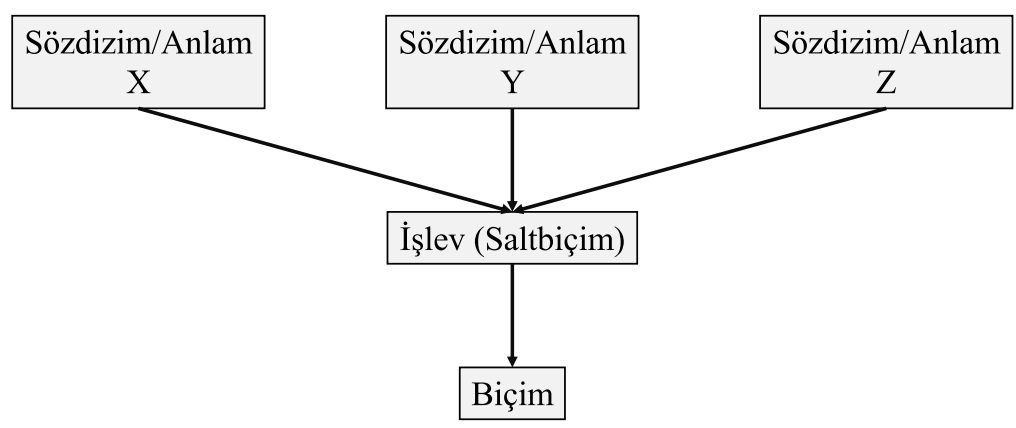

Şekil 1, X, Y, Z gibi farklı anlamsal/sözdizimsel özelliklere sahip birimlerin aynı biçimsel işlevle (görevle), farklı bir düzlemde birleşebileceğini ve bu ortak düzlemde saltbiçimsel bir özelliğin olduğunu ve bu özelliğin aynı biçimsel işlemleri tetikleyeceğini göstermektedir; Sözcük-ve-Dizil (Word-and-Paradigm) yaklaşımına dayanmaktadır. Benzer bir şekilde, Stump $(2001,2016)$ da çekimsel biçimbilgisini tartıştığı pek çok durumda, anlam/içerik dizilini ve biçim dizilini birbirinden ayırmaktadır: Anlam dizili dizimbiçimsel, biçim dizili ise saltbiçimsel özellikleri temsil etmektedir. Beard'ın (1995) da savunduğu anlambiçim ayrıklığı, O’Neill (2013) ya da Stump'ın (2016) modellerinde gördüğümüz gibi sözdizime ya da yalnızca anlama dayalı biçim tartışmalarının açıklayamadığı pek çok veriyi açıklamaktadır. Ayrıklık, örneğin, aynılaşmayı (syncretism), yani bir dizilde farklı değerlerin aynı biçimle gösterimini (İngilizcede yönelme ve belirtme durumunun adıllardaki gösterimi gibi), ya da yine Latincedeki etken-edilgen (deponent) eylem biçimlerini kolaylıkla açıklamaktadır. Latincede (ve Yunancada) etken-edilgen eylemler etken anlamlı

4 Maiden da (2011) bu gibi, anlamsal ya da sözdizimsel nedeni, dayanağı olmayan saltbiçimlerin konuşucular için psikolojik gerçeklikleri olduğunu gözlemlemiştir. 
olduğu halde edilgen biçimindedir. ${ }^{5} \mathrm{Bu}$ gibi aynılaşma içeren eylemler aynı anlamın (örneğin 'etken') farklı dizillerde farkl, hatta, beklenmedik, zıt değerde bir biçimle (edilgen biçimi) gösterilebileceğini ve yine anlamın ve biçimin ayrı düzlemler olduğu savını desteklemektedir. Sadler ve Spencer da (2001), saltbiçimsel olarak düşündükleri biçimlerin b-özelliklere (m(orphological)feature) sahip olduğunu düşünmekte ve bu tür özellikleri anlamdizimsel (semantic-syntactic) özelliklerden ayırmaktadır.

$\mathrm{Bu}$ kavramlaştırma ve yorumlamalara paralel olarak, biçimsel işlemlerde hem anlamsal, hem saltbiçimsel özelliklerin etkileşerek amaçlanan son biçimleri ürettiğini düşünebiliriz. O'Neill'ın (2013) Latincedeki üçüncü tabanı içeren biçimleri çözümleyen modelinde, ${ }^{6}$ örneğin, [+bitmişlik ortac1], [+gelecek ortac1] ve [+adeylem] gibi anlama dayalı özelliklerin olduğu bir düzlem (Stump'ın (2001) anlam dizili gibi), bu farklı anlamların ortak biçimini gösteren saltbiçimsel özellikten sorumlu bir başka düzlem, yani [+3. taban] özellikli saltbiçimsel düzlem (Stump'ın biçim dizili gibi), ve anlam ve biçimin eşleşmesinden sorumlu kuralları içeren diğer bir düzlem (Stump'ın dizil bağlaması gibi) vardır. ${ }^{7}$ Böyle ayrlk (separationist) bir model, aynı biçimi sergileyen birbirinden ayrı çeşitli anlamların tek bir temel anlama dayandırılması zorunluluğunu ortadan kaldırmaktadır. Kısaca bir biçimin birbirine benzer ya da benzemez çoklu anlamları ifadede kullanımı, temelde yatan bir anlamsal ya da sözdizimsel özelliğe değil saltbiçimsel özelliğe dayanmaktadır; çünkü bu gibi durumların pek çoğunda, farklı kullanımların her birinde bulunan bir kavramsal ya da anlamsal özellik yoktur; yukarıda olduğu gibi, örneğin 'gelecek' anlamının 'bitmişlik' anlamına dayandırılması durumunda anlamsal genelleme yapmak zordur.

Saltbiçimlerin varlığını ve gerekliliğini gösteren diğer bir veri de İngilizcede bitmişlik içeren yapılar, örn. she has understood 'anladı', ve edilgen yapılardır, örn. it was understood 'anlaşıldı'. Her ikisi de eylemlerin (alanyazınında geçmişlik ortacı olarak adlandırılan) edilgen ortaç biçimini içermektedir, yani $\mathrm{E}(\mathrm{ylem})_{3}$. Aronoff (1994: 24-25) anlamsal olarak bağlantısı olmayan edilgen ve bitmiş biçimlerin her ikisinde de aynı eylem biçiminin, $E_{3}$, kullanılmasını yine sözdizime, sese ya da anlama dayandırmak yerine saltbiçimsel düzleme ve saltbiçimsel işlevlere bağlamaktadır.

5 Örneğin, Yunanca érx-ete (gel-3.TEK.EDL) 'gelir' sözcüğü etken anlamlı ancak edilgen biçimlidir (örnek kaynağı: Haspelmath ve Sims, 2010: 182).

6 O’Neill (2013: 233-235) aynı çalışmasında İspanyolcada bitmemiş bilgi kipi biçimiyle pek çok anlamı ifade eden biçimleri de benzer şekilde açıklamakta, İspanyolcadaki durumu da tek bir genel anlam yerine ortak bir biçimsel özellik taşımaya dayandırmaktadır.

7 Latincedeki 3. taban durumuna ait ayrıntılı gösterimler için bkz. O'Neill (2013: $227-$ 230). 
Bu bölümde değinilen çalışmalar, bu çalışmanın anlam-biçim ayrıklığı ve bunun da ötesinde, anlamla etkileşmeyen saltbiçimlerin varlığı savlarını desteklemektedir. ${ }^{8}$ Kısaca, bir biçimin belli anlamları ifadede kullanılması, o biçimin bu anlamlardan birini ya da tamamını taşımasını gerektirmemektedir. Bunun yerine, bu biçimin dolaylı olarak ilgili anlamlarla etkileştiğini düşünmek, birbirinden ilgisiz anlamların ortak biçimlerini açıklamada tutarlılık sağlayacaktır. Kimi biçimlerse herhangi bir anlama dayanmadan ortaya çıkabilir, biçimsel nedenlerle.

\section{Taban Biçimlendiriciler}

Bu bölüm, bir önceki bölümde üzerinde durulan saltbiçim kavramının bir türü üzerinedir: taban biçimlendirici ya da taban-yapanlar (stem formative). $\mathrm{Bu}$ çalışmaya göre, taban-yapanlar, belli biçimsel/biçimyapısal işlemler için uygun olmayan girdileri uygun biçime getirmek, yani biçimsel işlemlerin gereksediği tabanları biçimlemektedir.

Karmaşı olmayan bir iki örnek verecek olursak, İngilizcedeki düzensiz iki çokluk biçimine bakabiliriz öncelikle. child-r-en 'çocuklar' ve ox-en 'öküzler' sözcük biçimlerinin her ikisinde de üretken olmayan -en çokluk eki vardır ancak yalnızca ilk sözcükte -en eki ve kök biçimin arasında bir başka (altı çizili) biçim vardır. - $r$ biçimi, kök biçime eklenerek çoğul çekimine girecek bağımlı bir tür taban oluşturmaktadır, child-r-, ve bu biçim olmadan çokluk sağlanamamaktadır, * childen. Bu nedenle - $r$ biçimi bir tür taban-yapan olarak değerlendirilebilir (bkz. Katamba, 1993: 47-48). ${ }^{9}$

Daha az kısıtlı diğer bir örnek de İngilizcedeki -al ekidir, syntactic-al-ly 'sözdizimsel olarak', semantic-al-ly 'anlambilimsel olarak' sözcüklerinde olduğu gibi. syntactic ve semantic sözcükleri sıfattır ancak sıfattan belirteç yapan, üretken türetim işlemi -ly eklenmesi öncesinde bir başka işlemden geçmektedirler; bu işlem bu sıfat tabanları yeniden biçimlendiren -al eklenmesidir ve burada da bir tür bağımlı biçim ve taban-yapan söz konusudur. Ancak unutmayalım ki -al taban-yapanı her -ly eklenmesinde bir ön koşul değildir, örn. clever-ly 'akıllıca'. Bu taban biçimlemesini ne tür tarihsel nedenler gerektirirse gerektirsin, önemli olan Modern İngilizcede syntactic-al-biçiminin, syntactic ve syntactically biçimlerinin aksine, bağımlı olması ve -ly eklenmesine bir ön koșul olmasıdır. Diğer bir taraftan aynı eklenme, -al, phon-o-logic-al 'sesbilimsel' ve morph-o-logic-al 'biçim(bilim)sel' sözcüklerinde de

8 Saltbiçimler için ayrıca bkz. Cruschina, Maiden ve Smith, 2013.

9 Katamba (1993: 48) children biçimindeki çokluk ekinin Eski İngilizcede -er olduğunu ve eskiden cild-er olan çoğul biçimin artık children olduğunu ifade etmektedir. Bu durum, yine de $-r$ - biçimini Günümüz İngilizcesinde taban yapma görevinden alıkoymamaktadır, çünkü *childen biçimi kullanılmamaktadır. 
yukarıdakinin tersi bir görev üstelenmiştir: $\mathrm{Bu}$ kez bağımlı biçimlerden, phonologic- ve morphologic-, bağımsız biçimler çıkarmaktadır, phonologic-al ve morphologic-al. Bu eklenmenin bu çalışma açısından önemi ise şu şekildedir: İster bağımlı ister bağımsız biçimler oluştursun, -al eklenmesinin yukarıdaki durumlarda anlama herhangi bir katkısı yoktur; bu da bir tür saltbiçimdir.

Son olarak da İtalyancadaki adlara ve sayı çekimlerine değinelim: İtalyancada adlar hem teklik hem de çokluk için çekimlenmektedir, örneğin, gatt$o$ (kedi-TEK) 'kedi', gatt-i (kedi-ÇOK) 'kediler'. Ancak iki sözcük biçiminde de taban olan gatt- bağımlı bir biçimdir ve bağımsız oluşamamaktadır (Haspelmath ve Sims, 2010: 21). Bu da bize şunu göstermektedir: İtalyancada ad tabanları bağımlı biçimlerdir; sayı çekimi için gerekli eklenmeler hem sayı değerinden sorumludur hem de bağımlı tabanlardan bağımsız biçimler üretmektedir, gatt-o, gatt-i bağımsızdır. Yani bunlar da bir tür taban-yapandır. Ancak yukarıdaki diğer örneklerden farklı olarak, İtalyancadaki taban-yapanlar saltbiçimsel değildir çünkü anlam içeren teklik ve çokluk değerlerini de kodlamaktadır.

\section{Türkçede Taban Biçimleme Var mıdır?}

Bu bölüm Türkçede de taban biçimlemenin olduğunu savunmakta ve üretken bir tür taban-yapanı tartışmaktadır: anlamla etkileşmeyen - $I$ eklenmesi. yaz- $\underline{\imath}-c l$, çiz-

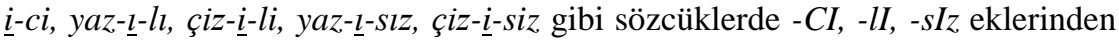
hemen önce bulunan - $I$ alanyazınında ne değinilmiştir ne de fark edilmiştir. Bunun yerine yukarıdaki ekler -ICI, -IlI gibi bütüncül algılanmıştır (örn. van Schaaik, 2002; Kharytonava, 2011; Gürer, 2014). Oysa ki bu sözcüklerde -I'nın ayrıklığı Türkçede biçimyapısına dair önemli çıkarımlara yol vermektedir: Türkçe gibi çoğunlukla bitişimli bir dilde de anlam-biçim eşleşmesinde bire-bir olmayan durumlar, ${ }^{10}$ ve bunun da ötesinde, anlam içermeyen biçimler vardır. $\mathrm{Bu}$ çalışmaya göre, yukarıdaki biçimlerdeki -I eklenmesi anlamla etkileşmeyen bir türdendir: saltbiçim.

Bu tür $-I$ eklenmesi anlamla ilgisizse neyle ilgilidir ve neden oradadır diye bir soru gelebilir akıllara. Bu sorunun yanıtı -I eklenmesinin anlamsal değil, sözdizimsel değil ama biçime/biçimyapısına dayalı ulamsal bir koşuldan ötürü eklenmesidir: anlam içermeyen biçimsel adlaştırma. ${ }^{11}$ Diğer bir deyişle, örneğin, çiz-í-ci sözcüğünde, türetilmiş son anlam olan ‘çizmeyi eyleyen' için öncesinde

10 Türkçede çekimsel dizillerdeki anlam-biçim örtüşmezlikleri için bkz. Erdem, 2018.

11 Bu çalışmaya göre ulam hem sözdizimi, hem sözlükçeyi, hem de biçimyapısını ilgilendiren bir kavramdır. Ulamın hangisine ait olduğuna dair bir seçim yapma zorunluluğu yoktur; bu bileşenlerin hepsi ulamsal özellikleri ilgilendiren kurallar ve düzenlemeler içermektedir. Örneğin, sözdizimsel bileşen belirli kurallarda belirli ulamların yan yana gelmesini sağlar ya da kısıtlarken, biçimyapısal bileşen belirli işlemlerde belirli ulamsal kurallar koyar, belirli ulamları taban olarak seçer. 
çiz-i biçimine karşılık gelen 'çizme eyleminin sonucu olan çıktı: çizgi' anlamına gerek yoktur; eylemin eyleyicisine eylemin çıktısı olmadan da gönderim yapılabilir, çiz-er ya da çiz-en'de olduğu gibi. Bence çizici çizdiklerinin farkında ifadesindeki çiz-i-ci'de, örneğin, çizi- ile eşleşen bir 'çizgi' ara anlamı yoktur, çiz-i-ci 'çizmeyi eyleyen' anlamındadır. Ancak yine de $-I$ eklenmesi vardır, *çiz$c i$ (ve *çiz-li 'çizilmiş', *çiz-siz 'çizilmemiş’ gibi biçimler) bu bağlamda dilbilgisidışıdır.

Diğer taraftan, çiz-i'de çıktısal ('çizgi') değil de çiz-me, çiz-iş ve çiz-im'de olduğu gibi $-m A$, - $(y) I s ̧$ ve -Im eklenmelerindekine benzer, olaysal/süreçsel bir adlaşma anlamı olduğu düşünülebilir. Ancak bu da doğru değildir çünkü çiz-i biçimi (ve diğer eylem+-I biçimleri) bağımsız oluştuğunda yalnızca çıktısal anlamla yorumlanabilmektedir: bu çiz-me-/çiz-iş-/çiz-im-/*çiz-i-nin bu kadar sürmesi ilginç ifadesinde, örneğin, süreçsel anlam yalnızca ilk üç adlaşmayla mümkündür. Kısaca çiz-i gibi eylem- $I$ biçimleri bağımsızken yalnızca çıktısal anlamla (örn. 'çizgi') eşleşmektedir ama bu anlam eylem-I biçimi bağımlıyken yoktur.

$c ̧ i z-i-c i$ ya da $y a z-\underline{-}-c l$ gibi sözcüklerde 'çizme/yazma eyleminin sonucu olan çıktı: çizi/yazı' (ara) anlamının gerekli olduğu ve türediği bir durum yok değildir elbette. Bu çıktısal ara anlam, son türemiş anlamın 'çiziyle/yazıyla ilgilenen, çiziyi/yazıyı seven, üstlenen... vb.' olduğu, -CI eklenmesinin 'eyleyici’ yerine 'uzman/ilgili' anlamıyla eşleştiği durumlardır, çizgi/çizi severler, çiz-i-ci-ler ya da çiz-i-ci grubu, sayı severler de başka bir grup olsun ifadesindeki gibi örneğin. $\mathrm{Bu}$ ifadedeki çiz-i-ci biçimlerindeki anlam çizi-ile eşleşen çıktısal 'çizgi' ara anlamını içermektedir; -CI eklenmesi de 'uzman/ilgili' anlamını beraberinde getirmektedir. Ancak yukarıda ilk olarak değinilen 'eyleyici' anlamı, yani çiz-i$c i / y a z-l-c l$ 'çizmeyi/yazmayı eyleyen', çıktısallık içeren bu anlamdan farklıdır.

Aynı biçimle, yani çiz-i-ci/yaz-l-cl sözcükleriyle, ifade edilen bu iki anlamı ayırt etmek önemlidir çünkü ilk anlam, 'eyleyici', kök anlam ile arasında bir ara anlam içermemektedir, ikincisi, 'ilgili', ise içermektedir. Bu çalışma açısından önemli ve ilginç olan ilk durumdur: 'çizme eyleyen' anlamındaki çiz-i-ci sözcüğünde ya da ‘yazma eyleyen' anlamındaki yaz-l-cl sözcüğünde arabiçimler (ya da önbiçimler) çiz- $i$ ve yaz-l gereklidir, ancak bu biçimlerin eşleştiği bir (çıktısal) anlam yoktur; böyle bir anlama gerek de yoktur. Benzer şekilde çiz-ili/yaz-l-ll, çiz-i-siz/yaz-l-sız sözcüklerinde de sırasıyla 'çizi/yazı içeren' ve 'çizi/yazı içermeyen' anlamları için (içerimsel anlamlar), arabiçim olan çizilyazı'nın 'çizme/yazma eyleminin sonucu olan çıktı' anlamına gerek varken ve bu anlam -I eklenmesiyle eşleşerek ara anlam olarak türerken, aynı sözcüklerin 'çizilmiş/yazılmış' ve 'çizilmemiş/yazılmamış' anlamları için, yani sonuçsal (resultative) anlamlar için böyle bir ara anlama gerek yoktur. 
Önemlidir ki anlamla eşleşmeyen -I eklenmesi yalnızca yukarıdaki gibi ad türeten $-C I$ ve sıfat türeten - $l I$ ve $-s I z$ eklenmeleriyle kısıtlı değildir: ${ }^{12}$ çiz-i-k, $a c ̧$ $l-k$, eriy- $i-k$ gibi sözcüklerde yine sonuçsal anlamla eşleşen $-k$ eklenmesinden

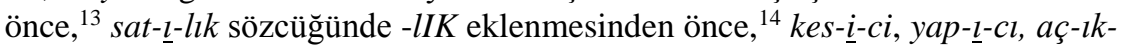
$l a-y l-c l$ gibi sözcüklerde bu kez sifat türeten -CI eklenmesinden önce herhangi bir ara anlama gerek yoktur ancak sözcükler tamamlanmadan önce -I süreci gerçekleşmekte ve çiz-i-, $a c ̧-l^{-}$, sat-l- gibi yalnızca ulamsal olarak yenilenmiş, anlam katmayan önbiçimler türemektedir.

$\mathrm{Bu}$ gibi ifadelerin hepsinde rastlantısal bir $-I$ sesi olduğunu ya da sonraki türetim eklerinin hepsinin $-I$ ile başlayabileceğini düşünmek yerine $-I$ ekini özenle değerlendirmek daha açıklayıcı olacaktır. Bu çalışmaya göre, anlam gütmeyen $-I$ eklenmesi, yukarıdaki durumların hepsinde ad türeten bir ara süreçtir; bir sonraki türetimlere koşuldur çünkü sonraki türetimlerin hepsi, öncesinde ad(laşmış) tabanlar gerektirmektedir. $-I$ ile ad tabanlar elde edilmeden bir sonraki işlem gerçekleşmemektedir. -I eklenmesi saltbiçimsel bir süreçtir. Anlam içermeyen ulamsal değişimi biçimyapısal işlem gerektirmektedir.

Yalnızca ulamsal değişim amaçlı -I eklenmesini bir kez daha aynı kök taban (çiz-) içeren biçimlerde inceleyelim:

$\begin{array}{ll}\text { a. } & \text { çiz-i-ci } \\ \text { a’. } & \text { çiz-i-ci } \\ \text { b. } & \text { çiz-i-siz } \\ \text { b’. } & \text { çiz-i-siz } \\ \text { c. } & \text { çiz-i-li } \\ \text { c'. } & \text { çiz-i-li } \\ \text { d. } & \text { çiz-i-lik } \\ \text { d'. } & \text { çiz-i-lik } \\ \text { e. } & \text { çiz-i } \\ \text { f. } & \text { çiz-i }\end{array}$

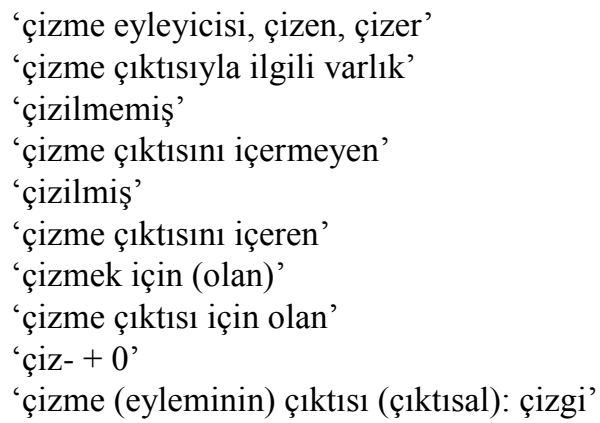

Yukarıda (1a, b, c, d)'deki arabiçim çiz-i'de (1f)'deki çıktısal 'çizgi' anlamına gerek yoktur çünkü (1a, b, c, d)'deki son türemiş anlamlar doğrudan bir

12 - II'dan önce anlam içermeyen $-I$ eklenmesi için şu örneklere de bakalım: yap-l-lı 'yapılmış', as-ı-ll 'asılmış', ger-i-li 'gerilmiş'.

13 Buradaki ek birim - $k$ ise biçimimiz yukarıda olduğu gibi bir ara - $I$ eklenmesiyle çiz-i$k$ şeklinde çözümlenecek, ancak söz konusu ek $-I k$ ise, yani /I/ sonuçsal eke ait bir parça ise, çözümlememiz ara $-I$ içermeden çiz-ik şeklinde olacaktır. Bu eklenmenin durumunu netleştirmek artzamanlı bir araştırmayı gerekli kılmaktadır.

14 - IIK eklenmesinden önce anlamla eşleşen - $m A$, - Im gibi (olaysal) adlaştırıcıların

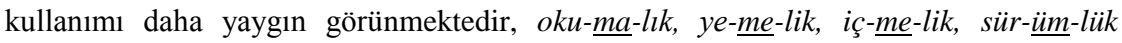
sıfatlarında olduğu gibi. 
eylemden (yukarıda kökten) türeyebilir niteliktedir. ${ }^{15}$ Örneğin (1a)'da çizmek eyleminden 'edici/eyleyen' anlamı türetirken diğer olası ara anlam olan (süreçsel) 'çizme süreci kavramı'na da gerek yoktur; benzer şekilde, (1c)'de çizmek eyleminden sonuçsal 'çizili' anlamın türetirken olası ara anlam olan 'çizme süreci kavramı'na gerek yoktur, ${ }^{16}$-lI türemesi doğrudan eylemin kök anlamından sonuçsal anlamı oluşturabilir. Kısaca (1a, b, c, d)'de -I eklenmesi zorunlu olduğu halde bu eklenmeyle gelen ve gereken yeni bir anlam yoktur.

Ancak (1a', b', c', d')'de durum farklıdır: Bu ifadelerde türeyen son anlamları elde etmek için (1f)'deki çıktısal ara anlam gereklidir. Örneğin, (1a')'da çizmek eyleminden önce (-I eklenmesiyle eşleşen) bir çıktı anlamı ('çizme çıktısı'), sonra da (-CI türetimiyle) 'bu çıktıyla ilgili bir varlık' anlamı türemektedir. Benzer şekilde, (1b'-c')'deki içerimsel anlamlar için önce çizmek eyleminden ' çıktı' anlamı, sonrasında da -lI ve -sIz eklenmeleriyle 'içerilen' ve 'içerilmeyen' anlamları türetilmektedir. İki grubu da düşündüğümüzde, $-I$ biçiminin her iki durumda da ulamsal değişime neden olduğunu, ancak yalnızca ikinci durumda anlamla eşleştiğini, ara anlama da gerek olduğunu, görüyoruz.

(1a', b', c', d')'de anlam-biçim örtüşmesi açısından herhangi bir ilginçlik yoktur: Her bir biçim bir anlama karşıllı gelmektedir; kök, ilk eklenme (-I ile) ve ikinci eklenme (türetim ekleri ile) ayrı ayrı anlamlarla örtüşmektedir. Üç biçim ve üç de anlam söz konusudur. Bu çalışma açısından asıl ilginç olan (1a, b, c, d) gibi ifadelerdeki durumdur: Üç biçim ancak bunlara karşlık gelen $i k i$ anlam vardır (kökün anlamı ve son türevin anlamı), ara eklenme olduğu halde ara anlam yenileme yoktur.

Şimdi de Türkçede eylemden eyleyici anlam türettiğimiz çiz-i-ci ("çiz-0Eyleyici') ve, örneğin, bu sözcügün İngilizcedeki karşıllğı olan draw-er ('çizEyleyici) sözcüğüne bakalım: Türkçede iki anlam için üç biçim varken İngilizcede aynı iki anlam için iki biçim vardır. Yani, türetimde anlam sayısının ve biçim sayısının eşit olmadığı durumlar olabilmektedir. Türkçede de aynı sözcük oluşumu için anlam-biçim eşitliği isteyecek olursak, o zaman biçimlerimiz çiz-i- $c i$ 'deki ' 0 ' yerine 'olaysal' ara anlam içeren çiz-im- $c i$ ya da çiz-me-ci gibi türetimler olurdu. Bu üç örnekteki ortaklık hepsinde $-C I$ öncesi

15 -I eklenmesiyle eşleşen (1f)'deki anlam Türkçede bağımsız bir biçimin anlamı olabilir, sözlükçeye de giriş yapabilir (ancak sözlükselleşmek zorunda değildir), örneğin, kork-u, yap-ı, tak-ı, say-ı, dürt-ü, duy-u. Benzer bir anlamla eşleşen -GI ve -DI adlaşmaları da sözlükçeye giriş yapmış çıktılara sahiptir: ör-gü, sev-gi, say-gl, duy-gu, gir-di, çık-tı gibi. Üretkenlik, kökün anlamsal özellikleri ya da tarihsel nedenlerle kimi eklenme süreçleri diğerlerinden daha sık kullanılabilir ve sözlükçede de daha çok çıktı bulundurabilir. Örneğin, 'çizme çıktısı' anlamıyla çiz-i'nin aksine çiz-gi sözlükçede yer edinebilmiştir.

16 Olaysal ara anlama gerek olsaydı biçimimiz çiz-i-ci yerine, örneğin, çiz-im-ci ya da çiz-me-ci olurdu. 
adlaşma gerçekleşmesi, farklılık ise amaç anlam olan 'çizme eyleyicisi' için çiz$i$-ci'nin toplamda iki, çiz-im-ci ve çiz-me-ci'nin ise toplamda üç anlam içermesidir.

Aynı anlamdaki çiz-i-ci'yi ('çizme eyleyen') bir de çiz-er ve çiz-en sözcükleriyle karşılaştırırsak, bu iki sözcükte de anlam eşitliği, biçimsel sayı eşitliği ancak ulamsal bir farklılık olduğunu görmekteyiz: - $A r$ ve $-(y) A n$ ekleri eylem kök tabanına doğrudan eklenebilirken, - $C I$ eki doğrudan eklenememekte ve öncesinde $-I$ eklenmesiyle gerçekleşen salt adlaşma sürecine girmektedir. $\mathrm{Bu}$ da Türkçede biçimyapısının -CI eklenmesi türünden süreçlere koyduğu bir taban koşulundandır: Bu tür bir eklenme ad tabanlara uygulanır. ${ }^{17}$

\section{Eski Türkçe Ne Gösteriyor?}

Bu bölümde yukarıda değinilen saltbiçimsel adlaşma süreçlerinin Eski Türkçede de olup olmadığına bakılmaktadır. Orhun Türkçesi ve Günümüz Türkiye Türkçesi arasında dolaysız bir bağlantı olmasa da, Türkçeye ait en eski yazılı verileri sağlaması açısından (Tekin, 1968: 7; Erdal, 2004: 5) bu lehçeye ait kimi ifadelere yer verilmektedir. Eski Türkçenin sunduğu saltbiçimsel adlaşma açısından önemli örnekler şu şekildedir:

(2) a. biti-g-ma 'yazan', biti- 'yazmak' (KT G 13, Tekin, 2003: 90)

b. $\quad$ kap- 'kapa(t)mak', kap-lg 'kap1' (BK D 15, Tekin, 2003: 89)

c. tir- 'yaşamak', tir-ig 'diri, canlı' (KT K 9, Tekin, 2003: 89),

öl- ‘ölmek', öl-üg ‘ölü’ (BK D 19, Tekin, 2003: 89)

d. $\quad a y-g u$-ç 'sözcü', $a y$ - 'söylemek' (T 10, Tekin, 2003: 90)

e. it-gü-çi ‘yapan, eden', it- 'yapmak, etmek' (KT K 13, Tekin, 2003: 90)

f. äzänçü 'gözetleyici', äzä- 'gözetlemek' (Altınköl I Ön 2, Tekin, 2003: 93), küzänçü 'koruyucu', küzä- 'korumak' (Altınköl I Ön 2, Tekin, 2003: 93)

17 Bu bölümde - I ile adlaşma içeren biçimlere yer verilmiş, bu ekle bağımsız çıktı oluşturmayan kimi eylem tabanlarına değinilmemiştir, örneğin koşu biçimi bağımsız da mümkünken yürüyü̈- bağımlıdır. İki eylem tabanı da geçişlilik açısından benzediğinden bu durumun nedeni geçişlilik değildir. Gelecek çalışmalarda, okuyu-, yürüyü-, başlaylgibi biçimlerin bağımsız kullanılmayışının Lewis (2000: 221)'deki gibi sesbilimsel bir nedenden mi (ünlü ile biten bir taban), anlamsal, üye-yapısal ya da sözlüksel görünüşle (Vendler, 1967) ilgili bir nedenden mi, yoksa yalnızca sıklığa dayalı sözlüksel (yürüyüş, okuma, başlama) engellemelerden mi kaynaklandığ ${ }_{1}$ araştırılabilir. Bu çalışma açısından önemli olan, bağımsız oluşmasalar da, bu gibi bağımlı biçimlerin hepsinin okuyucu, yürüyücü, başlayıcı gibi biçimlerde arabiçim göreviyle oluşması ve çalışmadaki ana savunmaya destek sunmasidır. 
Orhun Yazıtları (2a-e) ve Yenisey Yazıtları'na (2f) ait yukarıdaki sözcükler Eski Türkçede de anlamla eşleşmeyen adlaşma, yani yalnızca ulamı değiştirerek eylemden ad yapan, ancak anlamsal bir yenilik içermeyen türden - $(I) g,-g U$ ve $n$ eklenmelerini örneklemektedir. (2a)'daki $-m A$ adlaştırıcısı (Günümüz Türkçesindekinden farklı olarak) eyleyici anlamı türetmekte ancak (Günümüz Türkçesindeki - $C I$ gibi) eyleme doğrudan eklenememektedir ve öncesinde -(I)g adlaşmasına gereksinim duymaktadır. biti-g 'yazı' sözcüğü çıktısal anlamla bağımsız bir biçim olarak da kullanılmaktadır. Ancak biti-g-ma'daki ilk türev olan biti-g bağımlıdır, çıktısal bir ürün anlamına ('yazı') sahip değildir, çünkü biti-g-ma 'yazma işleminin eyleyicisi' anlamındadır. Bu nedenle bu örnekteki (I) $g$ adlaşması da yalnızca ulamı değiştiren türden bir taban-yapandır (Günümüz Türkçesindeki -I eklenmesi gibi).

(2b)'ye baktığımızda ise Günümüz Türkçesindeki kapa(t)- eyleminin eski kök biçiminin kap- olduğunu görüyoruz. $\mathrm{Bu}$ da bu çalışmaya sorun oluşturabilecek olası bir durumu açıklamaktadır: Türkçedeki kapa-lı sözcüğü sonuçsal anlam içermektedir ve daha önce tartışılan çiz-i-li, yaz-l-ll, yat-l-ll gibi örneklerden farklı olarak - $l I$ 'dan önce gereken adlaşmayı içermemektedir: *kapa-yl-ll. Bu biçimin Eski Türkçedeki olası biçimi de kap-l-ll biçimidir. (2b)'de ayrıca günümüzdeki kapı biçiminin eskiden kap-ıg olduğunu ve (2c)'de de günümüzdeki diri biçiminin eskiden dir-ig, ölü biçiminin de eskiden öl-üg, olduğunu görüyor ve günümüzde kimi sözcüklerde $-I g$ biçimindeki /g/ sesinin düşmüş olduğunu anlıyoruz: dirig, ölüg, kapıg gibi. Bu da şöyle bir varsayımı olası kılmaktadır: kapı sözcüğünün sözlükselleşmiş anlamı olası kap-ı-ll 'kapatılmış, kapalı' biçimine izin vermeyerek, ses değişimiyle şu anki kap-a-lı ve kapa- biçimlerinin oluşmasına neden olmuş olmalıdır. ${ }^{18}$ Bu biçimler de kapl- $l l$ 'kapatılmış' ya da kapa-yl-ll biçimlerini engellemektedir ve engellenen biçimlerin olmayışı çalışmanın savına bir sorun oluşturmamaktadır.

(2d, e)'deki sözcüklerde de 'eylemin eyleyicisi' anlamı için -CI eklenmesi öncesi bir başka adlaşma olan - $g U$ eklenmesi çıkıyor karşımıza: ay-gu-çı 'söyleyen, sözcü' ve it-gü-çi 'yapan, eden'. Bu örneklerde de, Günümüz Türkçesindeki $-C I$ önündeki $-I$ 'da olduğu gibi, $-g U$ ile gelen bir çıktısal ara anlama gerek olmadığından, Eski Türkçedeki $-g U$ ekinin de saltbiçimsel ulam değiştiren bir işleve sahip olduğunu savunabiliriz.

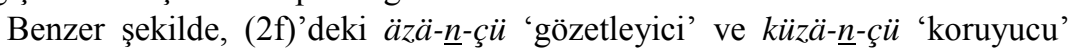
sözcükleri de, yine 'eylemin eyleyicisi' anlamı için -CI eklenmesini, ancak bunun öncesinde anlama katkısı olmayan $-n$ eklenmesini içermekte ve diğer bir saltbiçimsel adlaşma sürecini örneklemektedir.

18 Bu varsayım, yani eski kap- eyleminin günümüzdeki kap- $a$ - biçiminin ses değişimine uğramış $k a p-l-l l>k a p-a-l l$ 'dan geliyor olması, doğruysa kapa- eylemi bir tür biçimsel geri oluşum (back-formation) örneğidir. 
$\mathrm{Bu}$ bölümde tartışılan örnekler Türkçenin eski dönemlerden beri saltbiçimleme işlemlerine sahip olduğunu göstermiş, biçim ve anlam sayısının her zaman eşit olmayabileceği savını da desteklemiştir.

\section{5 Çözümleme: Biçimsel İşlemleme}

$\mathrm{Bu}$ bölüm, yukarıda değinildiği üzere, $-C I$, $-l I K$, - $l I$, -sIz gibi eklenmelerden önceki iki tür adlaşmayı, anlamla birleşen türü ve anlamla birleşmeyen türü, kurulum açısından karşılaştırmaktadır. çiz-im- $c i$ (-Im anlamla eşleşmektedir) ve çiz-i-ci 'çizen' (-I anlamla eşleşmemektedir) ya da konuş- $\underline{m a}-c l$ (-mA anlamla eşleşmektedir) ve konuş- $\underline{u}-c u$ 'konuşan' (-I anlamla eşleşmemektedir) sözcüklerinde olduğu gibi.

Bu çalışma, sözlükçeye (örn. Lapointe, 1980; Lieber, 1992) ya da sözdizime (örn. Baker, 1998; Harley, 2009) bağımlı olmayan, ancak bu bileşenlerle etkileşerek işleyen özerk bir biçimyapısal bileşen varsaymaktadır (Kunduracı, 2013). Biçimyapısal bileşende anlam ve biçim, birbiriyle eşleşen iki ayrı düzlemdir (Beard, 1995) ve durağan, sözlüksel biçimbirimler yerine etkin anlamsal ve biçimsel kurallar türetim ve çekimden sorumludur (örn. Aronoff, 1994; Beard, 1995; Pounder, 2000). Anlam ve biçimi bağımsız ancak etkileşim içindeki süreçler olarak varsayan çalışma, süreçsel bir biçimyapısı çerçevesinde, anlam, biçim ve ulamsal etkileşime dayalı türetim çözümlemeleri sunmaktadır. ${ }^{19}$

$\mathrm{Bu}$ varsayımlar doğrultusunda, Şekil 2, konuş-ma-cl ifadesinde olduğu gibi, iki eklenmede de anlam-biçim eşitliği içeren bir işlemleme örneği sunmaktadır:

19 Süreçsel biçimbilim modellerinde, ekler sözlüksel ya da hiyerarşik ağaç öğeleri olarak değerlendirilmez; eklerden çok eklenmeler (yani etkin süreçler) vurgulanır; ekler biçimsel işlemlere, biçimyapısal kurallara ait birimlerdir (bkz. Zwicky, 1986; Aronoff, 1994; Beard, 1995; Pounder, 2000; Kundurac1, 2013). 
Şekil 2. Eşit eşleşme

Türetim 1: amaç yapı: konuşmacı

İşlem/Süreç 1: - $m A$ eklenmesi

Anlamsal Kural (AK): 'x + olay-kavram' Taban/Girdi: $\{$ konuş $\}$

Biçimsel Kural (BK): $\{\mathrm{x}+-m A\} \quad$ Taban Türü: Eylem

Ulamsal Kural (UK): $\mathrm{E} \rightarrow \mathrm{A} \quad$ Türev/Çıktı:\{konuş-ma

Çıktı Türü: Ad

İşlem/Süreç 2: -CI eklenmesi

Anlamsal Kural (AK): 'x + eyleyici/ilgili’ Taban/Girdi: $\{$ konuşma $\}$

Biçimsel Kural (BK): $\{\mathrm{x}+-C I\} \quad$ Taban Türü: Ad

Ulamsal Kural (UK): A $\rightarrow$ A Türev/Çıktı: konuşma-cl

Çıktı Türü: $\underline{\text { Ad, }}$ Sıfat

Şekil 2, konuş- eylem kökünden konuşmacı biçimini türetmek için iki ayrı sürecin gerçekleştiğini gösterimlemektedir: İlk süreç olan - $m A$ eklenmesi birbirinden ayrı anlam, biçim ve ulam kurallarının birleşmesiyle gerçekleşmektedir; bu işlem eylemden olaysal varlık türeten, $-m A$ ekinin ekleneceği tabanın bir eylem olmasını gerektiren (bkz. Taban Türü) ve bir ad çıktısı veren bir süreçtir. Bunu izleyen ikinci süreç de $-C I$ eklenmesidir: yine üç ayrı kural eşleşmekte, bu kez tabanın ulamı değişmemekte $(A \rightarrow A)^{20}$ ve 'eylemin eyleyicisi' anlamında bir çıktı türetilmektedir: konuşmacı. ${ }^{21}$

$20-C I$ eklenme süreci, çıktı türü olarak iki seçenek sunmaktadır. Ad ve Sıfat. Yukarıdaki işlem ad türettiğinden bu ulamın altı çizilidir. Sifat türeve örnek olarak yırt-l-cl, kes-i-ci, $a k-\imath-c l$ gibi sözcükleri verebiliriz.

21 konuşmacı sözcüğünde (ve diğer $\mathrm{E}+m A+C I$ ) biçimlerinde bir diğer anlam daha mümkündür: olaysal 'konuşma eyleminin eyleyicisi' yerine çıktısal 'konuşma ile ilgili varlık' anlamı. - $C I$ süreciyle eşleşen 'eyleyici' anlamı ancak bir önceki $-m A$ süreciyle süreçsel anlam eşleşirse türemektedir; $-m A$ ile çıktısal anlam eşleşirse devamındaki - $C I$ eklenmesi 'ilgili varlık' anlamılla eşleşmektedir (örn. dondurmacı). 
Şekil 3. Eşitsiz eşleşme

Türetim 2: amaç yapı: konuşucu

İşlem/Süreç 3: -I eklenmesi

Biçimsel Kural (BK): $\{\mathrm{x}+-I\}$

Ulamsal Kural (UK): $\mathrm{E} \rightarrow \mathrm{A}$

Taban/Girdi: $\{$ konuş $\}$

Anlamsal Kural (AK): ' $\mathrm{x}+0$ '

Taban Türü/Koşulu: Eylem

Türev/Çıktı: $\{k o n u s ̧-u$ - $\}$

Çıktı Türü: A

İşlem/Süreç 2: - CI eklenmesi

Anlamsal Kural (AK): ' $\mathrm{x}+$ eyleyici/ilgili'

Biçimsel Kural (BK): $\{\mathrm{x}+-C I\}$

Taban/Girdi: $\{$ konuşu- $\}$

Ulamsal Kural (UK): $\mathrm{A} \rightarrow \mathrm{A}$

Taban Türü: Ad

Türev/Çıktı: konuşu-cu

Çıktı Türü: $\underline{\text { Ad, }}$ Sıfat

Şekil 3, konuş- eylem kökünden konuşucu biçimini türetmek için de iki ayrı sürecin gerçekleştiğini gösterimlemektedir: İlk süreç olan -I eklenmesi bir biçim kuralının bir ulam kuralıyla birleşmesiyle gerçekleşmektedir; bu işlem eylemden ad türeten, -I ekinin ekleneceği tabanın bir eylem olmasını gerektiren ve bir ad çıktısı veren bir süreçtir. Bu süreç, bu çalışmanın öne sürdüğü türden anlamsal yenileme içermeyen, yalnızca ulamsal ve biçimsel değişiklik içeren bir süreçtir: saltbiçimsel. Bunu izleyen ikinci süreç de yine - $C I$ eklenmesidir: Üç ayrı kural eşleşmekte, bu kez anlamsal kural da içerilmekte, tabanın ulamı değişmemekte $(\mathrm{A} \rightarrow \mathrm{A})$ ve yine 'eylemin eyleyicisi' anlamında bir çıktı türetilmektedir: konuşucu. $^{22}$

Özetle, Şekil 2 ve Şekil 3 biçimyapısal işlemlerin karmaşık olduğunu, anlamın, ulamın ve biçimin ayrı ayrı düzlemlere ait olduğunu ve bu üç düzlemin

$22 \mathrm{E}+m A+C I$ ' da olduğu gibi $\mathrm{E}+I+C I$ ' da da anlam belirsizliği söz konusudur aslında: $\mathrm{Bu}$ biçimlerdeki - $I$ eklenmesi hem Şekil 3'te olduğu gibi anlamsız olabilir, yalnızca ulamsal değişimi içerebilir ve devamındaki - $C I$ eklenmesi de yukarıdaki gibi 'eyleyici' anlamını içerebilir. Ya da $-I$ eklenmesi ' 0 ' yerine çıktısal anlamla eşleşerek devamındaki - $C I$ eklenmesinin 'ilgili varlık' anlamılla eşleşmesine neden olabilir. Örneğin, takıcı sözcügünü düşünelim: $-I$ ve ' 0 ' eşleşmesinde 'takan' anlamındaylen, $-I$ ve 'çıktı' eşleşmesinde 'takı satan/seven/ile ilgilenen' anlamındadır. 
üçünün de her işlemde devrede olmayabileceğini göstermektedir (Şekil 3, İşlem 3 , AK devre dışıdır). Anlam, biçim ve ulamın ayrıklığını kanıtlayan, eş sayıda olmayabileceğini gösteren başka örnekler de verilebilir:

(3) eski (Sifat) > eski-(Eylem)

AK: +

BK: 0

$\mathrm{UK}: \mathrm{S} \rightarrow \mathrm{E}$

(4) $\operatorname{çiz-i}(\mathrm{Ad}) \quad>\quad c ̧ i z i-l i(\mathrm{~S}$ fat $)$

$\mathrm{AK}_{1}$ : Eylem sonucu

$\mathrm{AK}_{2}$ : Edilgen

$\mathrm{BK}:+-l I$

$\mathrm{UK}: \mathrm{A} \rightarrow \mathrm{S}$

(3)’teki ifade biçimyapısal dönüşüm türünü örneklemektedir: Anlamsal ve ulamsal değişiklikler vardır ancak biçimsel bir iz yoktur. (4) ise daha önce değinilen biçimlerden birini içermektedir: $\mathrm{Bu}$ kez sonuçsal -lI eklenmesi, tek biçim, iki farklı anlamla eşleşmektedir: sonuçsal anlam ve edilgen anlam. Sözcük kökü, çiz-, etken bir eylem olsa da, $-I$ adlaşmasından sonraki - $l I$ içeren son türevde hem sonuçsal hem de edilgen anlam vardır. Sonuçsal anlam içeren çizili 'çiziye, çizime sahip' değil 'çizilmiş' demektir ve sonuçsallığın yanında edilgenlik de vardır ve böylece bir biçime iki anlamın düştüğü eşleşmezlik örneklerindendir.

\section{Bilişsel Dilbilgisine Karşı Saltbiçimleme}

Dilde nedensizlik, kısa ve özce, anlam ve biçimi ayıran, görüntüsellik (ikoniklik) yerine dile simgesellik kazandıran bir özelliktir (bkz. Saussure, 1967; Peirce, 1974; Haiman, 1985). Bilişsel Dilbilim gibi (örn. Lakoff, 1987; Langacker, 1991; Geeraerts ve Cuyckens, 2007) kimi modeller, dilde anlam-biçim ilişkisinin nedensizliğine karşıt tartışmalar sunmakta, Üretken Dilbilgisi ve nedensizliği kabul eden diğer özerk ve biçimsel modelleri dilde görüntüsel olarak düşünülebilecek pek çok olguyu görmezden gelmekle eleştirmektedir (örn. van Langendonck, 2007). Bu gibi bilişsel yaklaşımlar, görüntüselliğe oldukça geniş bir açıdan bakarak, dilde yansıma sözcüklerin yanında dilbilgisinde de görüntüsellikten bahsedilebileceğini, dilde biçimlerin genellikle kavramsal yapıyı yansıttığını ve bunun da görüntüsellik olarak düşünülebileceğini; kısaca anlam ve biçim arasında, özerk/biçimsel dilbilim modellerindeki görüşün aksine, çoğunlukla nedensel, yani dünyadaki varlık ve ilişkilere dayalı, bağlar kurulabileceğini öne atmaktadır. $\mathrm{Bu}$ görüş de bilişsel dilbilimin temel 
varsayımlarıyla paraleldir: Dil ve dilbilgisi, zihin ve işleyişi yerine, dünyayı ve dünyaya ait yapıları, özellikleri yansıtmaktadır (Langacker, 1991).

Ülküsel düşünüldüğünde dilde eşbiçimlilik (isomorphism) vardır: bir anlam için bir biçim kullanma durumu (bir-bir ya da bire-bir). Bire-birliğin, belirtililikle (markedness) de doğru bir orantı kurduğu düşünülür: Bir göstergenin biçimi ne kadar çok belirtili ve karmaşıksa anlamı da o kadar karmaşık olacaktır (Jakobson, 1966). Kısaca "ne kadar çok biçim o kadar çok anlam" deyişi, bilişselci yaklaşımlarda ön plandadır. Örneğin, van Langendonk (2007), dilde görüntüselliğin yansıma sözcüklerin ötesinde, biçimbilgisel ve sözdizimsel düzlemlerde de var olduğu kanısındadır. Biçimbilgisel olarak, örneğin, Endonezcede tekil biçim orang 'insan' ve çoğul biçimi orang-orang 'insanlar' anlam-biçim örtüşmesini, oranlı artışı ve eşbiçimliliği göstermektedir. Yine bu yaklaşımlarca İngilizcedeki çokluk gösterimi Endonezceye göre daha az birebirdir ancak buna rağmen, $-s$ çokluk ekinin daima çokluk belirtmesi bir tür birebirlik olarak değerlendirilmektedir. Van Langendonck'a (2007: 403) göre, iki durumda da belirtililik ilkesi işlemektedir, teklik eksiz (belirtisiz), çokluk ise ekli (belirtili) gösterime sahiptir; kavramsal belirtililik biçimbilgisine yansımaktadır. Sözdizimsel görüntüselliğe örnek olarak da kavramsal uzaklığın dilde sözcük dizimine yansıdığından bahsedilmektedir. Örneğin, dolaysız nesnelerin eylemlere daha yakın yerlerde belirmesi, ya da bilgisel/düşünsel/anlatımsal sıranın tümcelerde sözcük sırasına yansıması kavramsal yapının biçimsel görünümü ve yine dilde görüntüsellik, nedensellik olarak düşünülmektedir. Kısaca, bilişselcilikte dil biçimlerinin kavramsal bir ilke olan "yakınlık”tan yola çıkarak kurulduğu ve pek çok yerde görüntüselliğin ve eşbiçimliliğin aslında var olduğu savunulmaktadır (örn. van Langendonck, 2007).

Oysaki bu çalışma, (i) bilişselci yaklaşımın aksine, dilin yapısının, eşbiçimlilik ve görüntüsellikten bağımsız olduğunu ve (ii) anlam ve biçimin iki ayrı düzlem olduğunu göstermektedir. Ayrıca anlam içermeyen saltbiçimyapısal işlemlerin de gerçekleşerek biçimyapısının hem anlambilgisinden hem de sözdizimden ayrı değerlendirilmesi gerektiğini göstermeyi hedeflemektedir.

Öncelikle, yukarıda bahsedilen, görüntüselliği dilin her düzeyinde olağan ve gerekli gören yaklaşımlar görüntüselliği biçimbilgisinde örneklerken, önemli kimi noktaları göz ardı etmektedir: İngilizcede çokluk eki, örneğin, aynı zamanda tam tersi bir değeri de göstermektedir: teklik. $-s$ eki ad tabanlara eklendiğinde çokluk ancak eylem tabanlarında ('3. kişi' ve 'şimdi' değerleri ile birlikte) teklik değerini göstermektedir. Bu basit gibi görünen nokta aslında önemlidir çünkü bir biçimin aynı dilde ters değerler için kullanılması dilde görüntüselliğe açıça sorun oluşturmaktadır.

Benzer şekilde, tümcede sözcük sırasının görüntüsellikle bağdaştı̆̆ düşüncesi de pek çok farklı durumla çürütülebilir. Dolaysız nesne, dolaylıya göre eyleme anlamsal açıdan daha yakın olsa da, sözdizimsel açıdan bu yakınlığı zorunlu kılmayan diller vardır, Türkçe gibi. Sözcük diziliş kuralları kısıtlı olan 
İngilizce gibi dillerde bile farklı çatılar, gerektirdiği farklı kurallarla yakınlık dizilişini alabora edebilir. The book was given to the girl 'kitap kıza verildi' tümcesinde, örneğin, anlamsal düzeyde eylemin birinci üyesi, (the) book, ve eylem arasında bir yardımcı eylem, was, vardır ki bu biçim eyleme anlamca nesnelerden daha yakın değildir, yardımcı eylem tümcesel düzeyde ulam değerleri kodlamaktadır: zaman, kişi uyumu ve sınırlılık gibi. Kısaca ne biçimsel ne de sözdizimsel düzeyde görüntüselliğin ve biçimin anlama ya da kavramsal ilişkilere göre dizildiğinin bir güvencesi yoktur.

Önemli bir diğer nokta da biçimsel tür olarak çoğunlukla bitişimli bir dil olsa da Türkçede de bire-bir anlam-biçim eşleşmesi içermeyen kurulumların olmasıdır. Bu bölümden önceki bölümlerde tartışılan biçimlere ek olarak, örneğin, arkadaş-ı̣ sözcüğündeki çizili ek hem 'iyelik' hem de '1. kişi' değeri, yani aynı anda çoklu işlev içermektedir; arkadaş-t $t$ - $\underline{k}$ biçimindeki çizili ek de hem '1. kişi' hem de 'çokluk' değerleri taşımaktadır. Açıkça, bire-bir olmama durumu Türkçe gibi dillerde de çok uzak, sıra dışı bir durum değildir.

\section{Sonuç}

$\mathrm{Bu}$ çalışma, öncelikle, biçimyapısal işlemlere ait çıktıların, her zaman son biçim ve bağımsız olmayabileceğini göstermektedir. $\mathrm{Bu}$ da şu demektir: Biçimyapısının sözlükçeye aday birimler üretme (türetim) ve sözlükbirimleri gerektiğince biçimlendirme (çekim) dışında da görevleri vardır, bu çalışmanın sunduğu gibi, örneğin, arabiçim/önbiçim türetme. Arabiçimler hem türetim hem de çekim işlemleri sırasında çeşitli nedenlerle biçimsel olarak gereken ön işlemlerin sonucudur. Diğer bir deyişle, belirli amaç çıktılar, amaca giden yolda kimi ön işlemleri gerektirebilir, kes-i-ci (sıfat/ad) biçiminin öncesinde kes-i (ad) biçiminin türetilmesi gibi. ${ }^{23}$

Çalışmanın diğer bir göstergesi de Türkçede biçimsel ve anlamsal işlemlerin birbiriyle etkileşebilen ancak birbirinden ayrı işlemler olmasıdır; kısaca çalışma, biçim ve anlam ayrıklığını desteklemektedir (Beard, 1995). Çalışma, anlambiçim ayrıklığına yeni bir uzantı daha önermektedir: ulamsal ayrıklık. Ulamsal ayrıklık, ad, eylem gibi ulamların ne yalnızca anlam ne de yalnızca biçimle kısıtlanmadığ 1 , bu düzlemlerle etkileşen ayrı bir düzlem olduğu anlamına gelmektedir. Bu anlayış içinde ulamların hem sözlükçeyle, hem sözdizimle hem anlamla hem de biçimyapısıyla yakından ilgili olduğunu rahatlıkla söyleyebiliriz. ${ }^{24} \mathrm{Bu}$ çalışma, yalnızca ulamsal amaçlı biçimsel bir işlemin

23 Bu görüşe parallel bir çalışma olan Göksel (2001), Türkçede sözdizimsel gereği olmayan, yalnızca biçimyapısal güdülenme ve engellerden kaynaklı, ol- yardımcı eylemini içeren eylemcil yapılanmaları çözümlemektedir.

24 Türkçede ulam tartışmaları için örneğin bkz. Bozşahin, 2002; Uygun, 2009; Özge ve Bozşahin, 2010. 
anlamsal değişikliğe gereksinim duymadan gerçekleşebildiğini, saltbiçimsel işlemlerin ve çıktıların da dilbilgisinde var olduğunu ortaya çıkarmaktadır. Yukarıda 'kesici'deki amaç anlam için 'kesi' anlamının gerekmemesi ancak kesici biçimi için kesi'nin gerekmesi gibi.

Çalışma, diğer bir taraftan, taban-yapanların yalnızca çekimsel değil (örn. Latincede olduğu gibi, Aronoff, 1994) türetimsel biçimyapısınca da uygulanabildiğini, bu çalışmada sunulan taban biçimlendirmenin Türkçede bir tür türetim süreci olduğunu savunmaktadır. ${ }^{25} \mathrm{Bu}$ da türetimsel biçimyapısının anlam içeren aday sözlükbirimler türetmenin yanında anlam içermeyen saltbiçimsel birimler de üretebildiğini göstermektedir. Yalnızca biçimsel amaçla güdülen türevler de olasıdır.

Yalnızca biçimsel amaçla güdülen türevler, biçimyapısının dil dizgesindeki niteliğini betimlemeye de yardım eder. Türkçede biçimyapısının özerkliğini savunan diğer veri ve çalışmalar gibi, ${ }^{26}$ saltbiçimler ve saltbiçimsel işlemler de biçimyapısının kendine özgü doğasını ortaya çıkaran türdendir.

\section{Kaynaklar}

Aronoff, M. (1994). Morphology by itself: Stems and inflectional classes. Cambridge: MIT Press.

Baker, M. (1998). Comments on the paper by Sadock. S. Lapointe, D. Brentari ve P. Farrell (Yay.). Morphology and its relation to phonology and syntax içinde (s. 188212). Standford: CSLI Publications.

Beard, R. (1995). Lexeme-morpheme base morphology. Albany: State University of New York Press.

Bermúdez-Otero, R. (2007). Morphological structure and phonological domains in Spanish denominal derivation. F. Martínez-Gil \& S. Colina (Yay. haz). Optimalitytheoretic studies in Spanish phonology içinde (s. 278-311). Amsterdam: John Benjamins.

Bozşahin, C. (2002). The combinatory morphemic lexicon. Computational Linguistics, $28,145-186$.

Cruschina, S., Maiden, M. ve Smith, J. C. (2013). Boundaries of pure morphology: Diachronic and synchronic perspectives. Oxford: Oxford University Press.

Erdal, M. (2004). A grammar of Old Turkish. Leiden-Boston: Brill.

Erdem, M. (2018). Non-canonical morphological patterns in Turkish: Evidence from person-number markers (Yüksek Lisans Tezi). Boğaziçi Üniversitesi.

25 Diğer dillerdeki taban-yapanlar için bkz. Bermúdez-Otero, 2007 (İspanyolca); Kastovsky, 2006 (Eski İngilizce). Kastovsky (2006) de Eski İngilizcede taban-yapanların türetimsel birimler olduğunu düşünmektedir.

26 Bkz. Göksel, 1998, 2001, 2006; Kundurac1, 2013, 2015, 2017, 2018; Kundurac1 ve Göksel, 2016; Erdem, 2018. 
Geeraerts, D. ve Cuyckens, H. (2007). Introducing cognitive linguistics. D. Geeraerts ve H. Cuyckens (Yay. haz.). The Oxford handbook of cognitive linguistics içinde (s. 322). Oxford: Oxford University Press.

Göksel, A. (1998). Word size. G. Booij, A. Ralli ve S. Scalise (Yay. haz.). Proceedings of the first Mediterranean conference on morphology içinde (s. 190-200). Patras: University of Patras.

Göksel, A. (2001) The auxiliary verb at the morphology-syntax interface. E. Erguvanlı Taylan (Yay. haz.). The verb in Turkish içinde (s. 151-181). Amsterdam: John Benjamins.

Göksel, A. (2006). Pronominal participles in Turkish and lexical integrity, Lingue e Linguaggio, 5, 105-125.

Gürer, A. (2014). Adjectival participles in Turkish. Lingua, 149, 166-187.

Haiman, J. (1985). Natural syntax: Iconicity and erosion. Cambridge: Cambridge University Press.

Harley, H. (2009). Compounding in Distributed Morphology. R. Lieber ve P. Štekauer (Yay. haz.). The Oxford handbook of compounding içinde (s. 129-144). Oxford: Oxford University Press.

Haspelmath, M. ve A., D. Sims. (2010). Understanding morphology (2. Bs.). London: Hodder Education.

Jakobson, R. (1966). Implications of language universals for linguistics. T. A. Sebeok (Yay. haz.). Current trends in linguistics, vol. 3, Theoretical foundations içinde (s. 263-78). Mouton: The Hague.

Kastovsky, D. (2006). Typological changes in derivational morphology. A. van Kemenade ve L. Bettelou (Yay. haz.). The Handbook of the history of English içinde (s. 151-177). Oxford: Blackwell.

Katamba, F. (1992). Morphology. London: Macmillan.

Kharytonava, O. (2011). Noms composés en Turc et Morphème -(s)I (Doktora Tezi). The University of Western Ontario.

Kundurac1, A. (2013). Turkish noun-noun compounds: A process-based paradigmatic account (Doktora Tezi). University of Calgary.

Kundurac1, A. (2015). Türkçede aitlik ulamı ve biçimsel ifadesi. Dilbilim Araştırmaları Dergisi, 26(1), 43-62.

Kundurac1, A. (2017). Process Morphology in concatenation. Büyükkantarcioğlu, N., Özyıldırım, I. ve Yarar, E. (Yay. haz.), 45. Yıl Yazıları içinde (s. 255-278). Ankara: Hacettepe Üniversitesi Yayınevi.

Kundurac1, A. (2018). The paradigmatic aspect of compounding and derivation. Journal of Linguistics (published online on 22 Nov. 2018). https://doi.org/10.1017/S0022226718000518

Kundurac1, A. ve Göksel, A. (2016). Morphology: The base processor. J. Audrig, F. Masini ve W. Sandler (Yay. haz.), Quo Vadis Morphology - MMM Vol $10-$ Proceedings of the 10th Mediterranean Morphology Meeting içinde (s. 88-97). Universities of Leiden, Bologna and Haifa.

Lakoff, G. (1987). Women, fire, and dangerous things: What categories reveal about the mind. Chicago: University of Chicago.

Langacker, R. (1991). Foundations of Cognitive Grammar II: Descriptive applications. Stanford: Stanford University. 
Langendonck, W. van. (2007). Iconicity. D. Geeraerts ve H. Cuyckens (Yay. haz.). The Oxford handbook of cognitive linguistics içinde (s. 394-418). Oxford: Oxford University Press.

Lapointe, S. (1980). The theory of grammatical agreement (Doktora Tezi). University of Massachusetts.

Lewis, G. (2000). Turkish grammar. (2. Bs.). New York: Oxford University Press.

Lieber, R. (1992). Deconstructing morphology. Chicago: University of Chicago Press.

Maiden, M. (2011). Morphological persistence. M. Maiden, J. C. Smith ve A. Ledgeway (Yay. haz.) The Cambridge history of the Romance languages, Vol. 1 içinde (s. 155215). Cambridge: Cambridge University Press.

Matthews, P., H. (1972). Inflectional morphology: A theoretical study based on aspects of Latin verb conjugation. Cambridge: Cambridge University Press.

Mel'čuk, I. (1991). Subtraction in natural language. F. A. Bogusawski, M. Grochowski ve D.Weiss (Yay. haz.). Words are physicians for an ailing mind içinde (s. 279-293). Mnchen: Sagner.

O'Neill, P. (2013). Morphomes and morphosyntactic/semantic features. S. Cruschina, M. Maiden ve J. C. Smith (Yay. haz.). Boundaries of pure morphology: Diachronic and synchronic perspectives içinde (s. 221-247). Oxford: OUP.

Özge, U. ve Bozşahin, C. (2010). Intonation in the grammar of Turkish, Lingua, 120, 132175.

Peirce, C., S. [1931] (1974). Collected papers of Charles Sanders Peirce. C. Hartshorne ve P. Weiss (Yay. haz.). Cambridge, MA: Harvard University Press.

Pounder, A. (2000). Processes and paradigms in word-formation morphology. Berlin: Mouton de Gruyter.

Sadler, L. ve Spencer, A. (2001). Syntax as an exponent of morphological features. G. Booij ve J. van Marle (Yay. haz.). Yearbook of Morphology 2001 içinde (s. 71-96). Dordrecht: Kluwer.

Saussure, F. de. [1916] (1967). Cours de linguistique ge'ne'rale. Paris: Payot.

Schaaik, G. van. (2002). The noun in Turkish. Its argument structure and the compounding straitjacket. Wiesbaden: Harrassowitz Verlag.

Stump, G. (2001). Inflectional morphology. Cambridge: Cambridge University Press.

Stump, G. (2016). Inflectional paradigms: Content and form at the syntax-morphology interface. Cambridge: Cambridge University Press.

Tekin, T. (1968). A grammar of Orkhon Turkish. Uralic and Altaic Series 69. Mouton \& Co, TheHague: Indiana University Publications.

Tekin, T. (2003). Orhon Türkçesi grameri. Türk Dilleri Araştırmaları Dizisi 9. İstanbul: Mehmet Ölmez Yayınları.

Uygun, D. (2009). A split model for category specification: Lexical categories in Turkish (Doktora Tezi). Boğaziçi Üniversitesi.

Vendler, Z. (1967). Linguistics in philosophy. Ithaca, NY: Cornell University Press.

Zwicky, A. M. (1986). The general case: Basic form vs. Default Form. D. Feder, M. Niepokuj, V. Nikiforidou, M. van Clay (Yay. haz). Proceedings of the Annual Meeting of Berkeley Linguistics Society 12 içinde (s. 305-314). Berkeley: Berkeley Linguistics Society. 